\title{
A Simple Method of Estimating Wind Turbine Blade Fatigue at Potential Wind Turbine Sites
}

J. C. Barnard

L. L. Wendell

June 1995

Prepared for the U.S. Department of Energy under Contract DE-AC06-76RLO 1830

Pacific Northwest Laboratory

Operated for the U.S. Department of Energy

by Battelle Memorial Institute

*atsattelle 


\section{DISCLAJMER}

This report was prepared as an account of work sponsored by an agency of the United States Government. Neither the United States Government nor any agency thereof, nor Battelle Memorial Institute, nor any of their employees, makes any warranty, express or implied, or assumes any legal liability, apparatus, product, or process disclosed, or represents that its use would not infringe privately owned rights. Reference herein to any specific commercial product, process, or service by trade name, trademark, manufacturer, or otherwise does not necessarily constitute or imply its endorsement, recommendation, or favoring by the United States Government or any agency thereof, or Battelle Memorial Institute. The views and opinions of authors expressed herein do not necessarily state or reflect those of the United States Government or any agency thereof.

\section{PACIFIC NORTHWEST LABORATORY operated by \\ BATTELLE MEMORIAL INSTITUTE for the UNITED STATES DEPARTMENT OF ENERGY under Contract DE-ACO6-76RLO 1830}

Printed in the United Srates of America

Available to DOE and DOE contractors from the

Office of Scientific and Technical Information, P.O. Box 62, Oak Ridge, TN 37831: pricas available from (615) 576-8401

Available to the public from the National Technical Information Service, U.S. Department of Commerce, 5285 Port Royal Rd., Springfield, VA 22161 


\section{DISCLAIMER}

Portions of this document may be illegible in electronic image products. Images are produced from the best available original document. 
PNL-10630

A Simple Method of Estimating Wind Turbine Blade Fatigue at Potential Wind Turbine Sites

J. C. Barnard

L. L. Wendell

June 1995

Prepared for the U.S. Department of Energy under Contract DE-ACO6-76RLO 1830

Pacific Northwest Laboratory

Richland, Washington 99352 
. 


\begin{abstract}
This paper presents a technique of estimating blade fatigue damage at potential wind turbine sites. The cornerstone of this technique is a simple model for the blade's root flap bending moment. The model requires as input a simple set of wind measurements which may be obtained as part of a routine site characterization study. By using the model to simulate a time series of the root flap bending moment, fatigue damage rates may be estimated. The technique is evaluated by comparing these estimates with damage estimates derived from actual bending moment data; the agreement between the two is quite good. The simple connection between wind measurements and fatigue provided by the model now allows one to readily discriminate between damaging and more benign wind environments.
\end{abstract}





\section{Acknowledgments}

This work was supported by the U.S. Department of Energy under Contract DE-AC06-76RLO 1830. The Pacific Northwest Laboratory is operated for the U.S. Department of Energy by Battelle Memorial Institute. The authors graciously thank Lawrence Schienbein for his helpful comments and Ruth Keefe for her help in preparing this report. . 


\section{Contents}

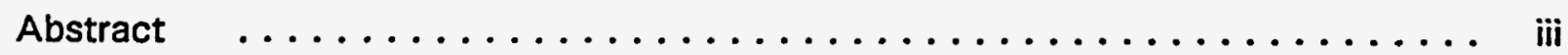

Acknowledgments $\ldots \ldots \ldots \ldots \ldots \ldots \ldots \ldots \ldots \ldots \ldots \ldots \ldots$

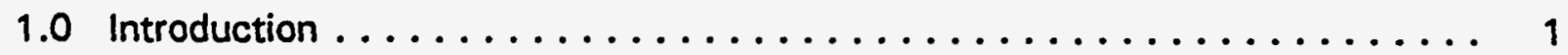

2.0 A Simple Relationship Between the Wind and the Root Flap

Bending Moment ........................ 3

2.1 Removal of the Blade Response $\ldots \ldots \ldots \ldots \ldots \ldots$

2.2 The Scaling Law . . . . . . . . . . . . . . . . . . 5

2.3 The Wind Data and Rotational Sampling $\ldots \ldots \ldots \ldots \ldots \ldots$

2.4 Finding the Function $G_{T}$ and the Constant $C_{4} \ldots \ldots \ldots \ldots$

3.0 Estimating Blade Fatigue Damage Rates Using the Modeled

Bending Moment ......................... 13

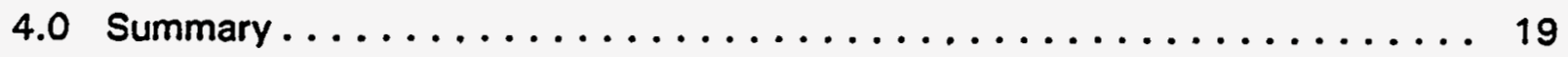

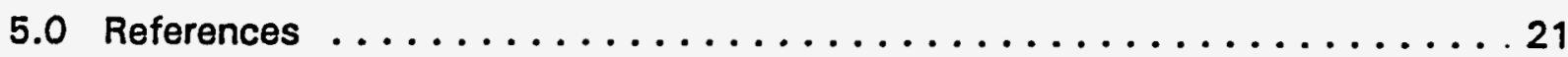




\section{Figures}

2.1 A Segment of a Times Series of the Filtered Bending Moment, $M_{\text {sero }}$, the Measured Bending Moment, $M_{b}$, and the Modeled Bending Moment, $M_{m} \ldots \ldots \ldots$

2.2 Spectra of the Filtered Bending Moment, $M_{\text {aero }}$ the Measured Bending Moment, $M_{b}$, and the Modeled Bending Moment, $M_{m} \ldots \ldots \ldots \ldots \ldots$

2.3a The Cycle-Averaged Bending Moment Plotted Versus the Cycle-Averaged Tip Speed Ratio .............................. 10

2.3b The Variation of the Bending Moment from the Cycle Average Plotted Versus

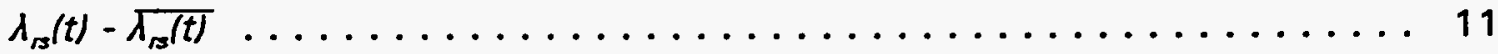

3.1 The Damage Rate Derived from the Measurements, $D_{\text {mossuremone, }}$ Plotted Versus the Modeled Relative Damage Rate, $D_{\text {modded }} \ldots \ldots \ldots \ldots \ldots \ldots \ldots$

3.2 The Damage Rate, $D_{\text {mosurement, }}$ Plotted Versus the Turbulence Intensity . . . . 15

3.3 The Rainflow Count Distribution of the Measured Bending Moment, with an Exponential Fit to LCHA Region (cycles/hour < 100) . . . . . . . . . . . 16

\section{Table}

2.1 The 22 NREL Data Cases $\ldots \ldots \ldots \ldots \ldots \ldots \ldots \ldots \ldots \ldots \ldots \ldots \ldots \ldots$ 


\subsection{Introduction}

As the wind industry has painfully learned, turbines located in certain places suffer from premature structural failure. In these places, some aspect of the wind's turbulence apparently poses a major threat to turbine longevity. If these sites could be identified during a preliminary resource characterization study, then the developer could avoid them when planning the layout of a wind plant. The identification of these sites requires some knowledge of the site's wind conditions that can best be obtained from wind measurements. However, to use these measurements profitably, one must know what to measure and how to connect these measurements to fatigue.

Historically, it has been assumed turbine fatigue is at least loosely connected with a common wind measurement known as the turbulence intensity (TI), defined as $\sigma_{\mathrm{u}} / \mathrm{U}$. The wind industry's familiarity with this quantity has led to a vague but persistent hope that the TI may be a suitable representation of a site's potential for wind-induced fatigue. The underpinning for this proposition appears to be based on the following logic: as implied by its name, TI measures "turbulence," and because turbulence and turbine fatigue are related, it then follows that $\mathrm{TI}$ and turbine fatigue must be related. This reasoning holds only if a direct connection between $\mathrm{TI}$ and fatigue can be established, but unfortunately, no such connection has been discovered. At the present time, one cannot state with certainty that sites with the largest TI must be the most damaging, and vice versa. Wendell et al. (1993) have even suggested that the turbulence intensity may be a misleading representation of turbine fatigue; that is, a high turbulence intensity may not necessarily be correlated with a large potential for fatigue damage. (In fact, we shall substantiate Wendell's claim and show that $\mathrm{TI}$ by itself is not correlated with fatigue damage rates.)

With Wendell's study in mind, it is clear that the search for a connection between measurements and fatigue must examine quantities other than the TI. To this end, Kelley (1994) took a broader view and considered not only the TI, but a number of other "turbulent" quantities as well. He showed that the low-cycle, high-amplitude (LCHA) part of rainflow count distribution for the root flap bending moment could be modeled by an exponential distribution described by an amplitude and a "slope." Kelley found that the slope was correlated with the hub-height Reynolds stress. A method of finding the distribution's amplitude was deferred to a future paper. Smedman (1992) derived a expression for the variation of the root flap bending moment, $\sigma_{M} / \mathrm{M}$, in terms of the normalized wind shear, $\Delta \mathrm{U} / \mathrm{U}$, and the $\mathrm{TI}$; this expression again suggests that the $\mathrm{TI}$ alone is not sufficient to characterize turbine (blade) damage. Smedman did not continue forth and relate $\sigma_{\mathrm{M}} / \mathrm{M}$ to fatigue damage, so it is not known to what degree her method would be successful in predicting a site's fatigue potential. Although these studies represent significant progress, the task of connecting simple wind measurements directly to turbine fatigue is still not complete, and a simple technique of doing this is now more than welcome. This paper presents such a technique. 
The technique presented here possesses the virtues of simplicity, low cost, and generality. In terms of instrumentation, three anemometers mounted on a single tower are all that is required. The anemometers are sampled at a rate of about $5 \mathrm{~Hz}$; the resulting wind time series are fed into a simple model to determine the fatigue potential of the site in question. (The wind time series need not be stored.) The required measurements can be made as part of a routine site characterization study. Our technique is also general, meaning that with some modification the principles that we set forth here may be applied to many turbines and turbine components. For the purpose of this paper, however, we shall examine only the fatigue damage at the blade root of a horizontal axis machine. 


\subsection{A Simple Relationship Between the Wind and the Root Flap Bending Moment}

The crux of our method is the discovery of a particularly simple relationship between a turbine's root flap bending moment and the measured inflow winds. This relationship is general in the sense that it is applicable to many different turbine designs. However, to demonstrate the practical use of this relationship, we must consider a specific turbine, and accordingly, we have chosen the modified Grumman Wind Stream 33 turbine associated with the National Renewable Energy Laboratory's (NREL's) combined experiment (Butterfield et al. 1992). The wealth of wind and turbine data emanating from this experiment allows our method to be rigorously examined.

The simple relationship mentioned above may be found in three steps, summarized as follows. Beginning with a time series of the actual, measured root flap bending moment, $M_{b}$, the blade response (i.e., the blade "flapping") is crudely removed from the time series through the use of a filter. This leaves an approximation for what we shall call the aerodynamic bending moment, $M_{\text {eero }}$. Second, an integral is written for the aerodynamic bending moment using strip theory. The essential aspects of this integral are then brought into clear view by a scaling procedure (similar in spirit to Jackson 1994) in which we show that a so-called "scaled" bending moment, $M_{s}$, is a function only of a rotationally sampled tip speed ratio, $\lambda_{r s}$, so that $M_{s}(t)=F\left(\lambda_{r s}(t)\right)$, where $F$ is some unknown function. $\left(M_{s}\right.$ is simply $M_{\text {sero }}$ divided by an appropriate scale factor.) Third, using the combined experiment's wind and turbine data we show how the shape of $F$ may be determined empirically from this data. The equation for $F$ provides an expression for $M_{s,}$ and therefore $M_{\text {aeror }}$ in terms of $\lambda_{r s}$. Because $\lambda_{r s}$ is easily determined from the measured winds, a simulated time series of the bending moment may now be calculated, and based on this time series, fatigue damage rates may be estimated.

\subsection{Removal of the Blade Response}

We now examine the first step, removal of the blade response. For this process, it helps to think of the bending moment as consisting of two interrelated parts: an aerodynamic forcing resulting from the lift and drag forces acting over the length of the blade, and the vibrations that arise in response to this underlying forcing (i.e., the blade response). The aerodynamic bending moment, $M_{\text {saro }}$ may now be defined more precisely as the bending moment that results solely from the aerodynamic forcing. The task of writing an integral for $M_{\text {eero }}$ in terms of the wind.is relatively easy, but describing both the forcing and its attendant response is much more difficult. Thus, if the blade response can be removed, an analysis of the wind/fatigue connection is made much easier.

An exact removal of the blade response from a time series of $M_{b}$ poses a very difficult inverse problem, and methods of attacking this particular problem are not readily available. 
Fortunately, considering the approximate nature of our work, such methods are unnecessary. Instead, we may crudely remove the blade response by applying a low-pass filter to $M_{b}$ so that in frequency space, the blade response is diminished at all frequencies both around and greater than the blade's fundamental frequency, $f_{o}$. This procedure is admittedly heuristic and rests on the proposition that most of the aerodynamic forcing occurs at the lower frequency part of the blade response spectrum, say less than about $2 P$ $\left(<f_{0}\right)$. Therefore, by filtering out the response at the higher frequencies $\left(\geq f_{0}\right)$ most of the blade response will be eliminated while retaining the bulk of the aerodynamic forcing. In practice, this procedure seems to work well enough for our purposes and, accordingly, we shall not pursue further justification here.

A simple low-pass filter was designed using a Gaussian function with a full-width-athalf maximum (FWHM) of 0.3 seconds. Using data from the combined experiment, the effect of the filter on a time series of $M_{b}$ is shown in Figure 2.1 , in which $M_{b}$ and $M_{\text {eero }}$ are both plotted. In this figure, the rapid oscillations of $M_{b}$ (the dashed line) clearly show the effect of the blade response at its fundamental frequency of $f_{o}=4.8 \mathrm{~Hz}$; this frequency is obviously absent in the filtered bending moment (the thick solid line). Because the rotation rate of the turbine is $72 \mathrm{RPM}$, the 1P frequency is $1.2 \mathrm{~Hz}$, and this frequency dominates the signal of $M_{\text {seror }}$. These conclusions are further confirmed in Figure 2.2, in which the spectra of the filtered and measured data are shown out to a frequency of $5 \mathrm{~Hz}$. The spike in the spectrum of the measured bending moment, at the blade's fundamental frequency,

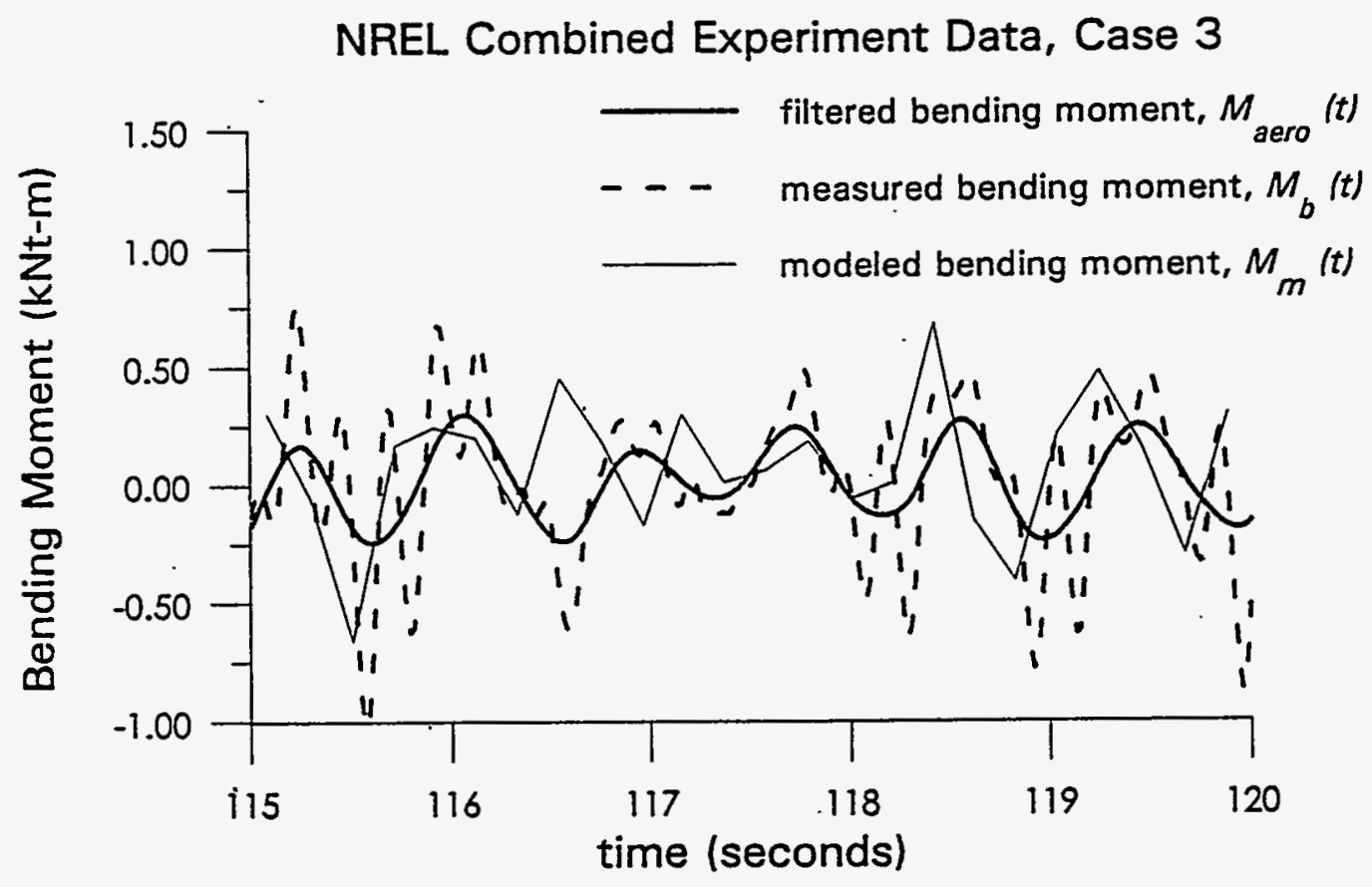

FIGURE 2.1. A Segment of a Times Series of the Filtered Bending Moment, $M_{\text {aero }}$ (thick solid line); the Measured Bending Moment, $M_{b 0}$ (the dashed line); and the Modeled Bending Moment, $M_{m}$ (thin solid line). 


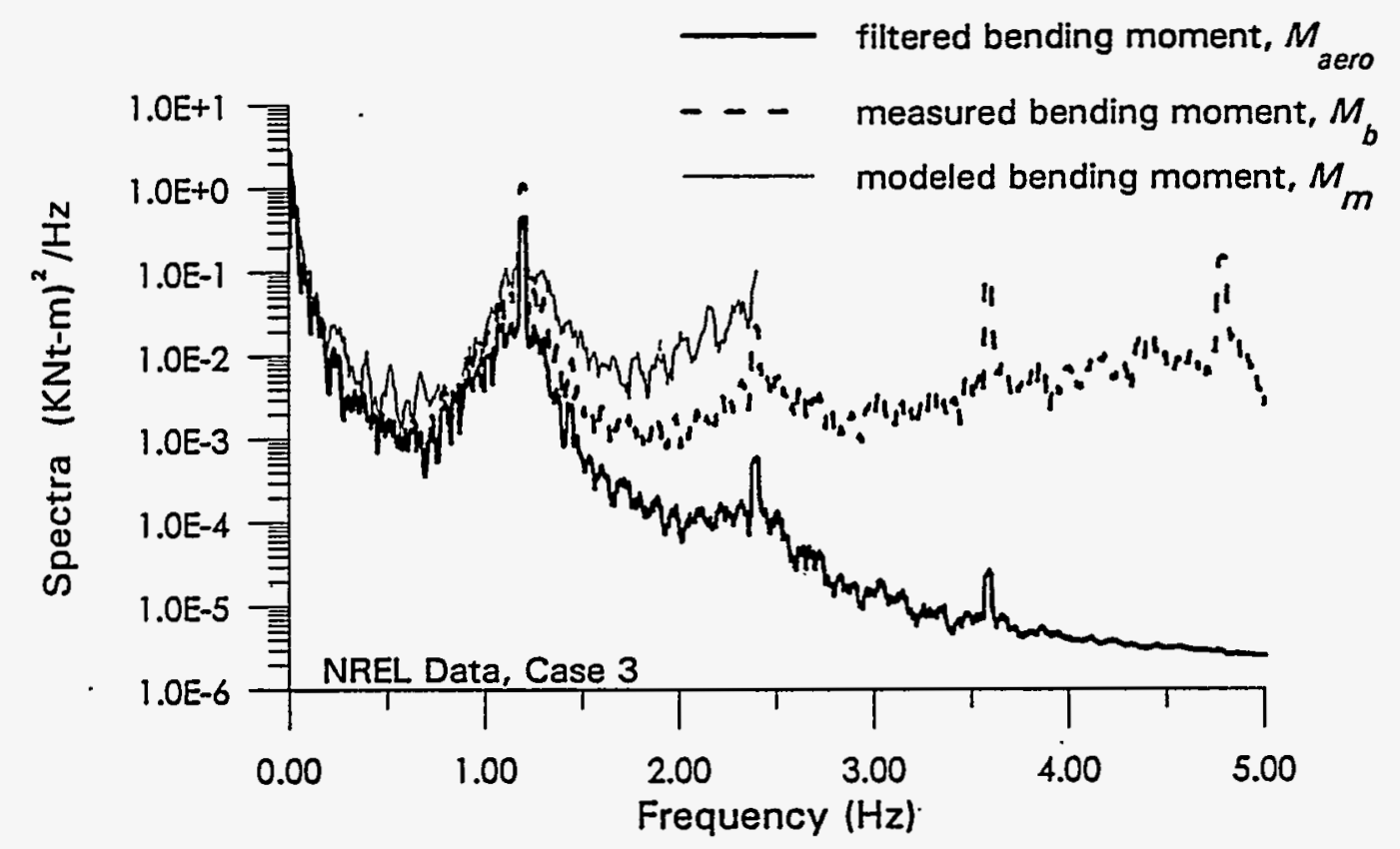

FIGURE 2.2. Spectra of the Filtered Bending Moment, $M_{\text {aeror }}$ (thick solid line); the Measured Bending Moment, $M_{b}$ (the dashed line); and the Modeled Bending Moment, $M_{m}$ (thin solid line).

$f_{o}=4.8 \mathrm{~Hz}$, is clearly evident. In the filtered spectrum, the spectral energy about this spike is substantially reduced. Near the $1 \mathrm{P}$ frequency $(1.2 \mathrm{~Hz})$ the filter's effect is not strong, and the spectral energy in the 1P peak is roughly the same for both the measured and filtered time series. Therefore, we conclude that a substantial portion of the underlying aerodynamic forcing is retained in the filtered signal.

\subsection{The Scaling Law}

The filtering has recovered, at least in an approximate sense, the aerodynamic bending moment, $M_{\text {sero }}$. With this quantity known, we may now write an integral for $M_{\text {sero }}$ using the well-known strip theory (Wilson 1994). For ease of exposition, we shall assume the case of a fixed-pitch turbine with a constant blade chord and twist. NREL's combined experiment turbine conforms to these expectations. However, with a minimal effort, the analysis presented here may be easily extended to more complicated turbine designs, including variable-pitch machines and perhaps teetered rotors (although we have yet to examine these cases in detail).

For a fixed pitch machine, strip theory tells us that the aerodynamic force acting over a blade element of length, $d r$, in a direction normal to the plane of rotation, is given by $F^{N}(r, t) d r$ : 


$$
\begin{gathered}
F^{N}(r, t) d r=\frac{1}{2} \rho C U^{2}(r, t)\left((1-a(x))^{2}+x^{2}\left(1+a^{\prime}(x)\right)^{2}\right) \times \\
\left(C_{L}(x) \cos \phi(x)+C_{D}(x) \sin \phi(x)\right) d r .
\end{gathered}
$$

Following the conventional nomenclature, $U(r, t)$ is the freestream horizontal wind speed impinging on the blade element at time, $t$, and a distance, $r$, from the hub, normal to the plane of rotation; $\rho$ is the air density; $C$ is the blade chord; $a(x)$ and $a^{\prime}(x)$ are the usual induction factors, $C_{L}(x)$ and $C_{0}(x)$ are the coefficients of lift and drag, respectively; and $\phi(x)$ is the angle that the relative wind makes with the plane of rotation. In Equation (1), the dependence of these aforementioned quantities on the key parameter, the "local" tip speed ratio, $x$, has been explicitly noted. $x$ is defined as

$$
x(r, t)=\frac{\Omega r}{U(r, t)}
$$

where $\Omega$ is the rotation rate of the turbine. Note that $x$ is also a function of $r$ and $t$. In this simple analysis, the root flap bending moment is simply the integrated force times distance, or $M_{\text {seer }}(t)=\int F^{N}(r, t) r d r$. After dropping the explicit dependence of $U$ and $x$ on the radius and time, the integral for $M_{\text {aero }}$ is

$$
\begin{aligned}
M_{\text {Qsro }}(t)= & \frac{1}{2} \rho C \int_{0}^{R} U^{2}\left((1-a(x))^{2}+x^{2}\left(1+a^{\prime}(x)\right)^{2}\right) \times \\
& \left(C_{L}(x) \cos \phi(x)+C_{D}(x) \sin \phi(x)\right) r d r .
\end{aligned}
$$

We now ask, can this integral be cast in a form that will illuminate the connection between the wind and the bending moment? Yes! We first assume that $U(r, t)$ is constant over the length of the blade, and we call this speed the rotationally sampled blade velocity, $U_{s}(t)$. This velocity may be thought of as the undisturbed, horizontal speed that would be seen by a point located near a rotating blade's center of force llocated at a distance $O(R)$ from the hub]. This definition of $U_{r s}$ explicitly recognizes the influence of rotational sampling (George and Connell 1984) on the response of the root flap bending moment. With the definition of $U_{r s}$ established, and the variable substitution, $r=\left(x U_{r g}\right) / \Omega$ (i.e., the $x$ becomes the independent variable instead of $r$. Equation (3) may be written as:

$$
\begin{gathered}
\frac{M_{\text {aerd }}(t)}{\frac{1}{2} \rho U_{r s}^{2}(t) C R^{2}}=\frac{1}{\lambda_{r s}^{2}(t)} \int_{x=0}^{x=\lambda_{r r}(t)}\left((1-a(x))^{2}+x^{2}\left(1+a^{\prime}(x)\right)^{2}\right) \times \\
\left(C_{L}(x) \cos \phi(x)+C_{D}(x) \sin \phi(x)\right) x d x
\end{gathered}
$$


where the $\lambda_{r s}(t)$ is the rotationally sampled tip speed ratio, defined as $\lambda_{r s}(t)=\Omega R / U_{r s}(t)$. The quantity on the left side of Equation (4) is a non-dimensional or "scaled" bending moment, $M_{s}$, given by:

$$
\cdot M_{s}(t)=\frac{M_{\text {aero }}(t)}{\frac{1}{2} \rho U_{s s}^{2}(t) C R^{2}}
$$

while the right side is a function only of the rotationally sampled tip speed ratio. Thus, we may infer the scaling law

$$
M_{s}(t)=F_{T}\left(\lambda_{s}(t)\right)
$$

where $F_{T}$ is an unknown function. The subscript " $T$ " reminds us that $F_{T}$ depends on the particular turbine under consideration. Equation (6) distills all the information contained in Equation (4) into a form which is so compact and simple that an important insight is gained: the scaled bending moment and therefore $M_{\text {sero }}$ depends only on $\lambda_{r s}$. We have therefore connected a measurable quantity, $\lambda_{r s}$, to the bending moment.

However, if we want to apply the scaling law to a specific turbine, then the functional form of $F_{T}$ must be discovered. This discovery relies upon simultaneous wind and turbine observations. Specifically, for a given turbine, one needs the rotationally sampled wind, $U_{r s}$ from which $\lambda_{r s}$ is calculated; and simultaneous measurements of the root flap bending moment, $M_{b}$, from which $M_{s}$ is found. A curve fitting exercise then relates $\lambda_{r s}$ to $M_{s}$. This exercise is made more convenient if the scaled bending moment is decomposed into a cycled-averaged part plus a deviation from the cycle average, $M_{s}(t)=\overline{M_{s}(t)}+\left(M_{s}(t)\right.$ - $\left.\overline{M_{s}(t)}\right)$. The overbar denotes the cycle average, defined as the time average over one blade revolution, $T$,

$$
\overline{M_{s}(t)}=\frac{1}{T} \int_{-\pi 2}^{\pi / 2} M_{s}\left(t+t^{\prime}\right) d t^{\prime}
$$

We then postulate that the cycle-averaged part, $\overline{M_{s}(t)}$, is a function only of the cycleaveraged tip speed ratio, or $\overline{M_{s}(t)}=G_{T}\left(\overline{\lambda_{s}(t)}\right)$. We further postulate that instantaneous variation from the cycle average, $M_{s}(t)-\overline{M_{s}(t)}$, is linearly proportional to the difference of the instantaneous tip speed ratio from the cycle-averaged tip speed ratio, or $M_{s}(t)-\overline{M_{s}(t)}=$ $C_{4}\left(\lambda_{s g}(t)-\lambda_{s 3}(t)\right) . C_{4}$ is the constant of proportionality, to be determined. The modified scaling law for $M_{s}$ is then 


$$
M_{s}(t)=G_{T}\left(\overline{\lambda_{r s}(t)}\right)+C_{4}\left(\lambda_{r s}(t)-\overline{\lambda_{r s}(t)}\right) .
$$

The first term of this equation may be interpreted as the contribution to the bending moment by rotor-size eddies and is therefore akin to the engulfing gust concept introduced by Wendell et al. (1993). The second term represents the instantaneous fluctuations experienced by the blade, and as such is loosely analogous to Wendell's concept of fluctuating shear. To find $M_{s}$ in a useful form, we must find the function $G_{T}$ representing the engulfing gusts, and the constant $C_{4}$, a measure of the strength of the fluctuating shear. These quantities are found by a curve. fitting procedure.

\subsection{The Wind Data and Rotational Sampling}

Before discussing the curve fitting in detail, it is first necessary to briefly describe the data used for this study. The data were collected as part of NREL's combined experiment during which detailed turbine and wind information were obtained. The data have been organized into 5-minute segments. For our study, we have obtained 22 such segments from NREL. Table 2.1 lists the mean speed and the turbulence intensity associated with these cases. The wind data come from a dense array of anemometers placed upwind of the turbine and are supplied in time increments of $0.0192 \mathrm{~s}(52.08 \mathrm{~Hz})$. Motivated by our desire for practicality, we have decimated the wind data to form a subset of data that conforms to the following two requirements. First, only data from three anemometers on a single upwind tower are used. These anemometers are deployed on the central tower of the combined experiment's vertical plane array, and the lower and upper anemometers are located a distance of $0.8 \mathrm{R}$ from the hub-height anemometer. ( $R$ is $5 \mathrm{~m}$ for the combined experiment's turbine blade.) Second, the wind data are decimated in time to conform to a nominal sampling rate of $4.8 \mathrm{~Hz}$. Such a rate corresponds to exactly one quarter of a blade revolution, or a time increment of $\Delta t=0.25 / \Omega \approx 0.208 \mathrm{~s}$.

When sampling at the above rate, the rotational sampling scheme needed to find $\lambda_{r s}(t)$ (and therefore $\lambda_{r s}(t)$ ) is made particularly simple. Starting with the blade in an upright position, the upper anemometer is sampled first at, say, time $t=0$, to measure $U_{s} / t=$ $0) . \lambda_{r s}(t=0)$ is found immediately from its definition presented above. Next, at time $t=$ $\Delta t$ we sample the hub-height anemometer, corresponding to the blade in the 3:00 o'clock position. Now we have $\lambda_{r s}(t=\Delta t)$. The lower anemometer is then sampled (the blade pointing downward, $t=2 \Delta t$ ) giving $\lambda_{s}(t=2 \Delta t)$; followed by another sampling of the hubheight anemometer (blade in 9:00 o'clock position, $t=3 \Delta t$ ) from which $\lambda_{r s}(t=3 \Delta t$ ) is calculated. The rotational cycle is closed by going to the upper anemometer $(t=4 \Delta t)$ and the process repeats again. The time lag between the two samplings at hub height crudely accounts for the wind's horizontal shear (Connell et al. 1988). 
TABLE 2.1. The 22 NREL Data Cases.

\begin{tabular}{ccc}
\hline NREL Case & $\begin{array}{c}\text { Average Wind } \\
\text { Speed }(\mathrm{m} / \mathrm{s})\end{array}$ & $\begin{array}{c}\text { Turbulence } \\
\text { Intensity }\end{array}$ \\
\hline 1 & 14.2 & 0.26 \\
2 & 14.7 & 0.16 \\
3 & 8.3 & 0.14 \\
4 & 11.2 & 0.14 \\
5 & 10.4 & 0.19 \\
6 & 10.4 & 0.15 \\
7 & 11.4 & 0.14 \\
8 & 7.3 & 0.14 \\
9 & 17.0 & 0.19 \\
10 & 7.4 & 0.17 \\
11 & 8.6 & 0.14 \\
12 & 7.7 & 0.19 \\
13 & 17.5 & 0.21 \\
14 & 18.9 & 0.14 \\
15 & 17.4 & 0.20 \\
16 & 10.6 & 0.12 \\
17 & 13.6 & 0.14 \\
18 & 14.3 & 0.16 \\
19 & 14.8 & 0.15 \\
20 & 16.1 & 0.16 \\
21 & 14.2 & 0.26 \\
22 & 8.0 & 0.21 \\
\hline
\end{tabular}

\subsection{Finding the Function $G_{T}$ and the Constant $C_{4}$}

If our modified scaling law (Equation [81) is indeed correct, then we know that $\overline{M_{s}(t)}$ is a function of $\lambda_{r s}(t)$ only. Therefore, a plot of $\overline{M_{s}(t)}$ versus $\overline{\lambda_{r s}(t)}$ should collapse on a single curve described by $G_{r}$. Our hope is that this curve can be modeled by some simple function, such as a polynomial in $\lambda_{r s}(t)$. For NREL data cases 4,10 , and 13, Figure 2.3a shows $\overline{M_{s}(t)}$. plotted versus $\lambda_{r s}(t)$. Each plotted point (a cross) represents a "measurement" of these quantities taken at the discrete time intervals $\Delta t \quad \approx 0.208 \mathrm{~s}$ ). (To account for the distance between the tower and the turbine, the wind data must be lagged in time relative to the bending moment data.) The scaled data do indeed collapse on a single curve, and fortuitously, the curve is represented well by a parabola, $G_{7}\left(\lambda_{\lambda_{5}}(t)\right)=C_{1}+C_{2} \lambda_{r s}(t)+$ $C_{3} \lambda_{s}(t)^{2}$. A least squares fit to the scaled data then provides the polynomial coefficients, or $C_{1}=-0.823, C_{2}=1.39$, and $C_{3}=-0.304$. 


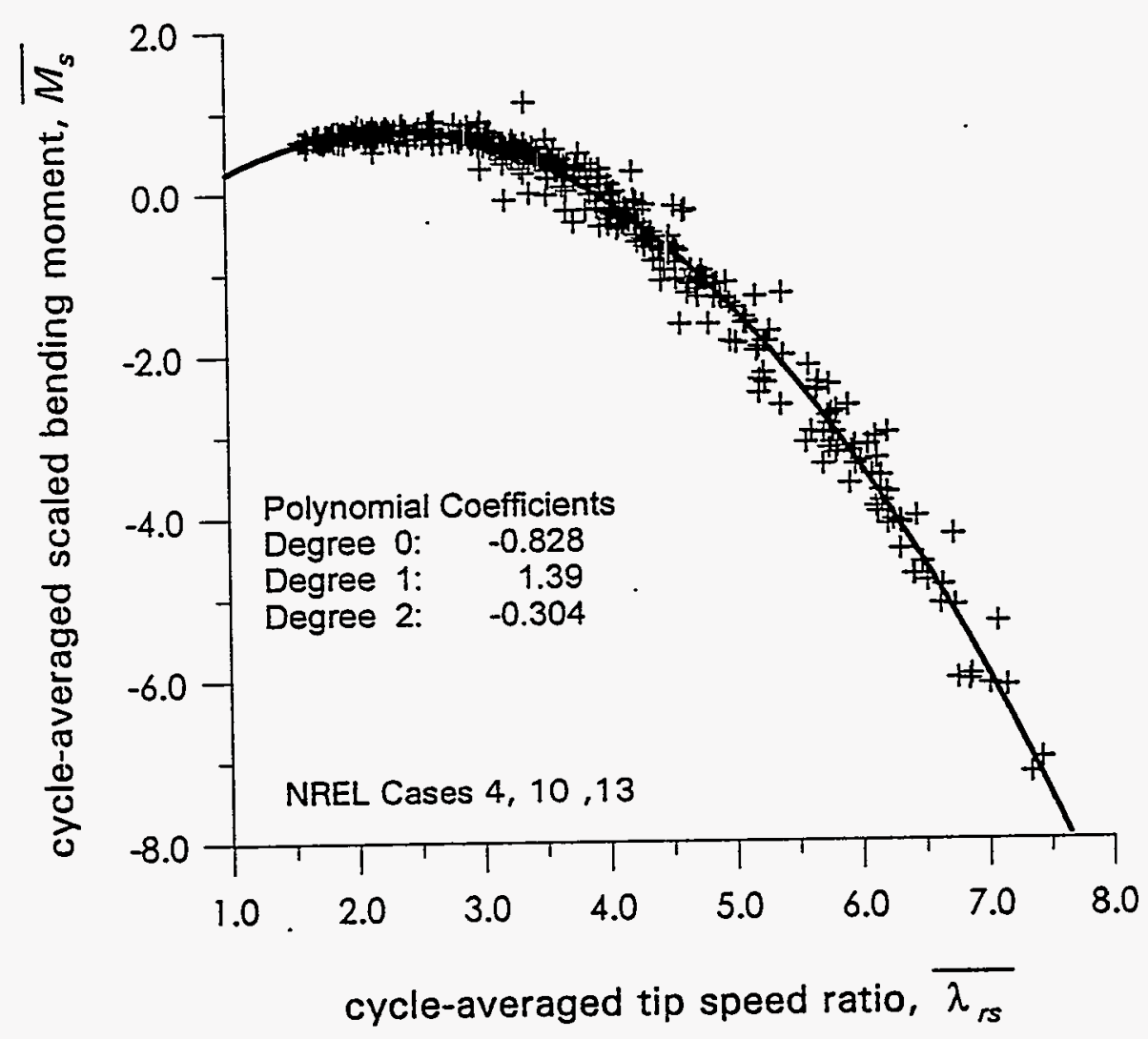

FIGURE 2.3a. The Cycle-Averaged Bending Moment Plotted Versus the CycleAveraged Tip Speed Ratio. The solid line is a parabola fit to the data.

In Figure 2.3b, the variation of the bending moment, $\left(M_{s}(t)-M_{r s}(t)\right)$, is plotted versus $\lambda_{r s}(t)-\overline{\lambda_{r s}(t)}$. A collapse of these data to a single curve is much more problematic than for previous case. There is still, nevertheless, a weak correlation between the two quantities; we model this relationship as a line passing through the origin. This line is indicated in Figure 2.3b. The slope of this line is the constant, $C_{4}$; therefore, $\left(M_{s}(t)-\overline{M_{r s}(t)}\right)=$ $C_{4}\left(\lambda_{r s}(t)-\lambda_{r s}(t)\right)$, where $C_{4}=2.9$. This specific value for $C_{4}$ was determined by an simple optimization procedure that minimized the difference between the damage rate (defined in Section 3), inferred from the bending moment model (Equation [10] below) and the damage rate estimated using the actual bending moment data. This optimization was based on data from only the three NREL data cases 4,10 , and 13.

The complete model for $M_{s}$ is

$$
M_{s}(t)=C_{1}+C_{2} \overline{\lambda_{r s}(t)}+C_{3} \overline{\lambda_{r s}(t)^{2}}+C_{4}\left(\lambda_{r s}(t)-\overline{\lambda_{r s}(t)}\right)
$$




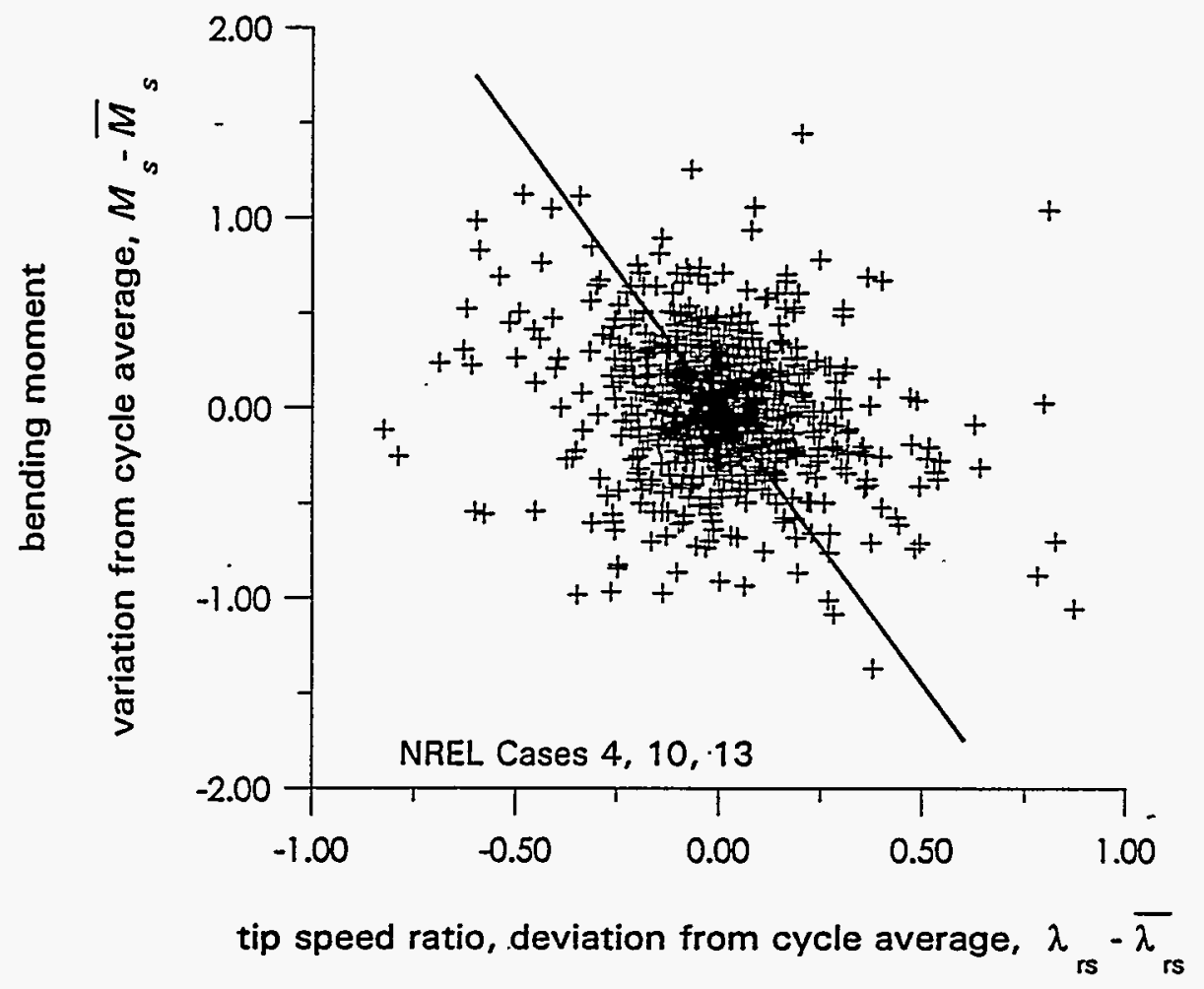

FIGURE 2.3b. The Variation of the Bending Moment from the Cycle Average Plotted Versus $\lambda_{r s}(t)-\overline{\lambda_{r s}(t)}$. The solid line is a linear fit to the data.

To convert from the scaled aerodynamic bending moment to the modeled (dimensional) 'bending moment, $M_{m}$, we simply.multiply $M_{s}$ by the scaling factor, $1 / 2 \rho \overline{U_{s s}(t)^{2} \mathrm{C}} \mathrm{R}^{2}$, in this manner

$$
M_{m}(t)=\left(C_{1}+C_{2} \overline{\lambda_{r s}(t)}+C_{3} \overline{\lambda_{r s}(t)^{2}}+C_{4}\left(\lambda_{r s}(t)-\overline{\lambda_{r s}(t)}\right)\right) \frac{1}{2} \rho C \overline{U_{r s}(t)^{2}} R^{2}
$$

The power of the scaling procedure to simplify a complex problem is now clear. Of all possible variables, we have determined that the scaled bending moment depends only on the rotationally sampled tip speed ratio (Equation [6]). The functional form of this dependence can be then inferred empirically from the data. Scaling has therefore achieved an important goal by reducing a seemingly complex problem, relating the aerodynamic bending moment to the inflow wind, to the simple expression embodied in Equation (10).

Of course, Equation (10) only approximates the aerodynamic bending moment, $M_{\text {serro }}$ and in turn, the aerodynamic bending moment is only an approximation of the true bending moment, $M_{b}$, because, among other things, $M_{\text {aero }}$ does not include the blade response. If so desired, the response can be restored to $M_{\text {sero }}$ through the use of an ad hoc blade 
model. We tried such an approach and were able to simulate the important features of the bending moment spectrum, particularly the spectral peak at the fundamental blade frequency, $f_{0}=4.8 \mathrm{~Hz}$ (see Figure 2.2). However, we found that our estimates of blade root fatigue were not significantly improved when the blade response was accounted for. Apparently, the high-frequency motions of the blade contribute mostly to the rainflow count distribution in the high-frequency, low-amplitude region unimportant to fatigue life (assuming a high-exponent material). Therefore, in the interests of simplicity, we decided to dispense with the blade model and take Equation (10) alone as a representation of the true bending moment. One may now ask, how well does this simplification work?

The thin solid lines in Figures 2.1 and 2.2 are the modeled bending moment, $M_{m}$, and the modeled bending moment spectrum, respectively, calculated from Equation (10). The fact that the modeled bending moment is calculated at intervals of $0.208 \mathrm{~s}$ is obvious in Figure 2.1; the high-frequency components associated with the blade response are missing. This is also evident in Figure 2.2, in which the spectrum of the modeled bending moment exhibits 1P peak and part of the 2P peak. Because the sampling of the wind speed occurs at $4.8 \mathrm{~Hz}$, only frequencies up to $2.4 \mathrm{~Hz}$ can be captured in our bending moment model. Despite these deficiencies, the amplitude fluctuations of modeled bending moment approximately follow the corresponding fluctuations of the measured bending moment. For example, in Figure 2.1 the fluctuations of both the measured and modeled bending moments are relatively large between 115 and $116.5 \mathrm{~s}$, they both decrease between $116.5 \mathrm{~s}$ and $118 \mathrm{~s}$, and both increase thereafter.

The ability of our model to track the fluctuations of the measured bending moment indicates satisfactory performance. We do not expect our simple model to exhibit pointby-point agreement with the measurements. Rather, we want the model to approximately capture the large bending moment fluctuations most responsible for fatigue damage. If this is the case, then model-derived rainflow cycle counts in the LCHA region should be roughly the same as counts obtained from the measured data and, therefore, damage estimates based on the model should be reasonably close to damage estimates derived from the measured data. 


\subsection{Estimating Blade Fatigue Damage Rates Using the Modeled Bending Moment}

The goal of this section is to compare damage estimates derived from the measured and modeled bending moments. For each of the 22 cases presented in Table 2.1, wind data are rotationally sampled at $4.8 \mathrm{~Hz}$, converted to $\lambda_{r s}$ and then fed into Equation (10) to produce a time series of the modeled bending moment. These time series are rainflow counted (Downing and Socie 1982) yielding the well-known distribution of cycle frequency (cycles/hr) versus cycle amplitude $(\mathrm{kNt}-\mathrm{m})$. The same rainflow counting algorithm is also applied to the corresponding time series of measured bending moment (sampled at time increments of $0.0192 \mathrm{~s}$ ). Once the cycle distributions are known for the modeled and measured cases, the nominal damage rate, $D$, is easily found for both cases. If we denote these two rates as $D_{\text {mossurement }}$ and $D_{\text {modded, }}$ then the agreement between these two damages provides a basis for assessing our technique. It is important to keep in mind the subscript "measurement" affixed to $D_{\text {messurament }}$ means we are calculating an estimated damage rate from a rainflow count distribution of the measured bending moment data (as opposed to $D_{\text {modeded }}$ which is an estimated rate obtained from the modeled bending moment).

The damage rate is found using the bending moment cycle count distribution in the following manner. Let the S-n curve for the material in question be denoted by $N\left(S_{\curvearrowright}\right)=$ $C_{a} S_{\infty}^{-b}$ where $N$ is the number of cycles to failure, $S_{a}$ is the nominal stress amplitude, and $C_{a}$ is a constant. Then, from Miner's rule (for example, see Sutherland et al. 1995), the damage rate is

$$
D=\frac{1}{C_{a}} \int_{0}^{\infty} n\left(S_{a}\right) S_{a}^{b} d S_{a}
$$

where $n\left(S_{a}\right)$ is the cycle-count distribution density for the stress amplitude (with units of cycles/hr/stress amplitude). The units of $D$ are $\left(\right.$ time $^{-1}$, so that $1 / D$ is the predicted lifetime. If we convert bending moment to a nominal stress using the usual relationship $S$, $=M_{c} c / l$, the damage rate-integral may be written as

$$
D=C^{\prime} \int_{0}^{\infty} n\left(M_{a}\right) M_{a}^{b} d M_{a}
$$

where $C^{\prime}$ is another constant that depends on the blade material. In this analysis, only wind-induced estimates of damage are sought, and in keeping with the approximate nature of our model, we have neglected a myriad of other factors that contribute to damage, such as the mean stress and stress concentration. Furthermore, because we do not know the 
material properties of the turbine blade in question, we set $C^{\prime}$ equal to 1 , realizing we can now only calculate damage rates relative to one another. For the comparisons that we are performing in this section, only relative damage rates are necessary.

Assuming a value of $b$ (13.5) appropriate for a composite material used in wind turbine blades (Mandell et al. 1993), the relative damage rates, $D_{\text {mossurement }}$ and $D_{\text {modded }}$ for all 22 data cases have been calculated using Equation (12) from the cycle count distributions of the measured and modeled bending moments. The two rates are compared in the scatterplot of Figure 3.1. The agreement shown in this figure is quite good. Clearly, the modeled damage rates serve as a good predictor of the damage rates calculated using the measured bending moment. We note in passing that if the fluctuating shear term in Equation (10) is turned off by setting $C_{4}$ equal to zero, the agreement between the modeled rates and measured rates is severely degraded. This demonstrates that the wind fluctuations experienced by a rotating blade contribute substantially to the time variation of the bending moment. Because a single hub-height anemometer cannot capture these fluctuations, modeling a bending moment time series using only hub-height wind speeds is not expected to be successful.

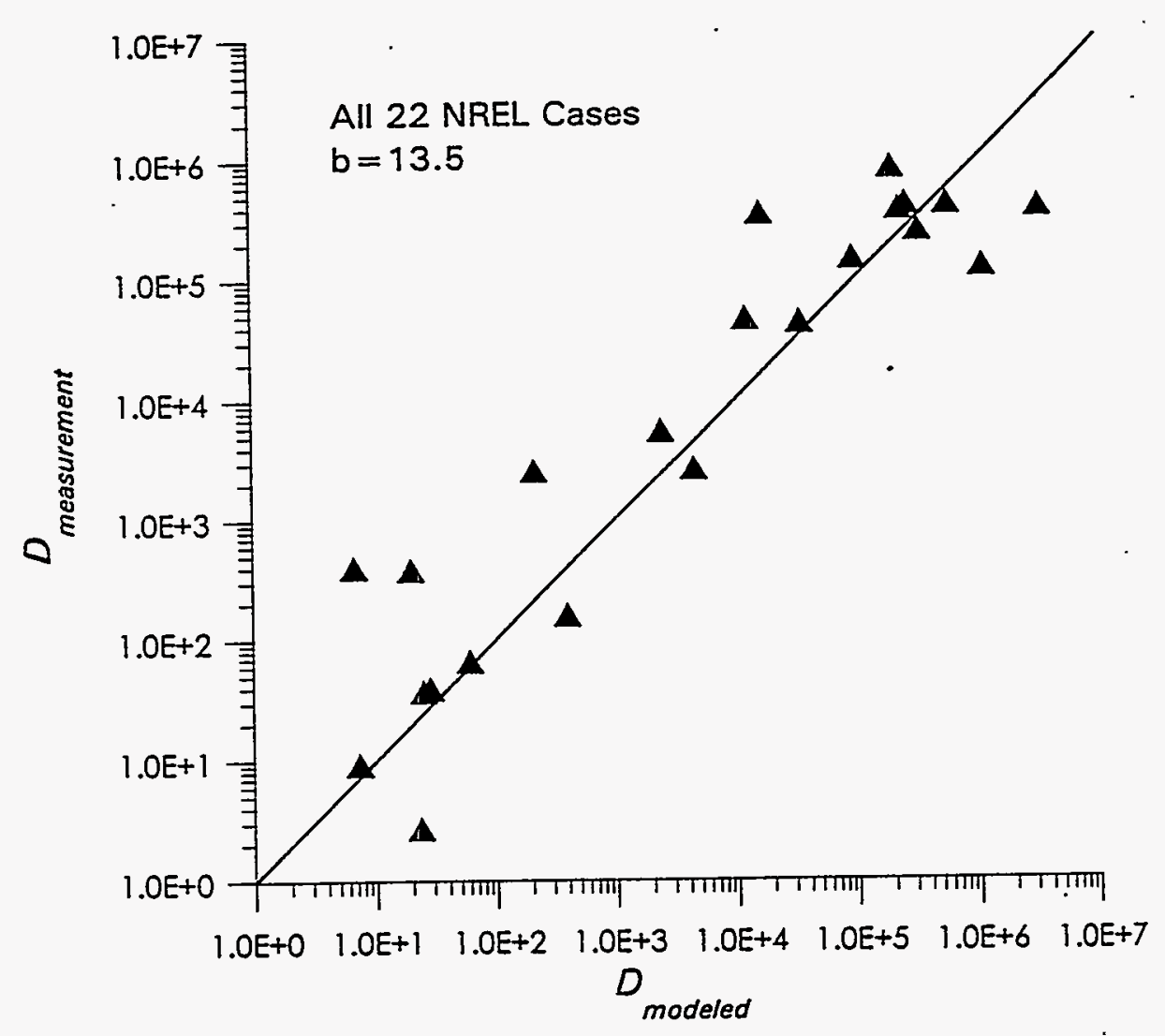

FIGURE 3.1. The Damage Rate Derived from the Measurements, $D_{\text {mossurement }}$ Plotted Versus the Modeled Relative Damage Rate, $D_{\text {modelese }}$. 
For the sake of comparison, suppose we try to predict damage rate using turbulence intensity. If $D_{\text {mossuramont }}$ is plotted versus turbulence intensity, what we hope to discover by casual observation is a relationship between the two that could be described by some equation. Then, given the turbulence intensity at another site and/or time, the equation could then be used to predict damage. Figure 3.2 shows the damage rate derived from the measured bending moment, $D_{\text {massurament }}$ plotted versus turbulence intensity. Obviously, there is no discernible relationship between the damage rates and the turbulence intensity. For these cases, the turbulence intensity would be a particularly poor predictor of fatigue damage rates.

Finally, the rainflow count distributions for all 22 cases added together are examined in Figure 3.3 in which the measured distribution is indicated by the crosses and the modelderived distribution by the triangles. An exponential model fit to the distributions in the LCHA region is indicated by the thick solid lines, along with the equation that describes the parameters of the model, $\beta_{o} \exp (-\beta, M)$, where $\beta_{o}$ and $\beta_{1}$ are the amplitude and slope, respectively.

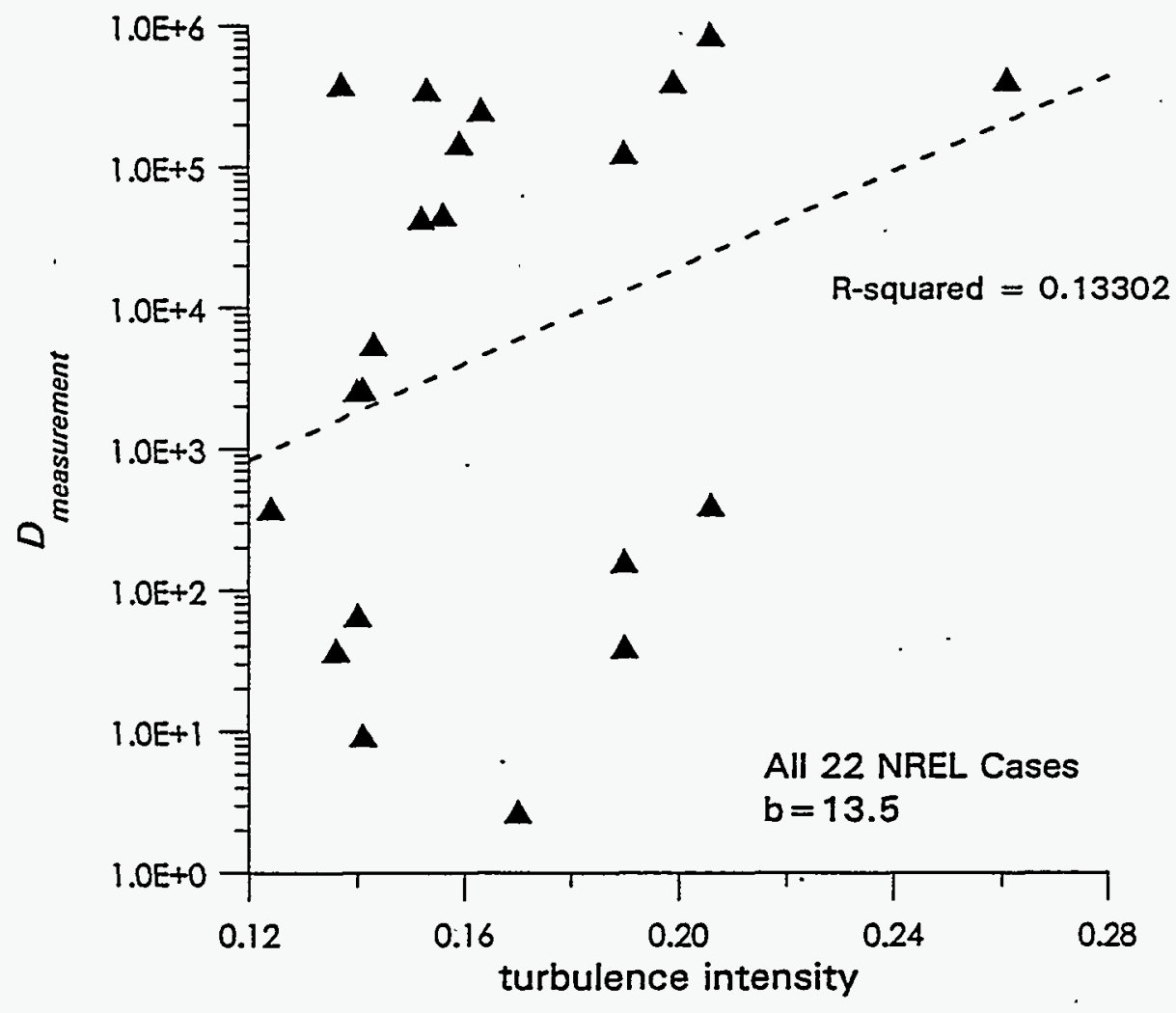

FIGURE 3.2. The Damage Rate, $D_{\text {monsuremenz, }}$ Plotted Versus the Turbulence Intensity. The dashed line is a linear fit to the points. The correlation $\left(r^{2}\right)$ is very poor. 


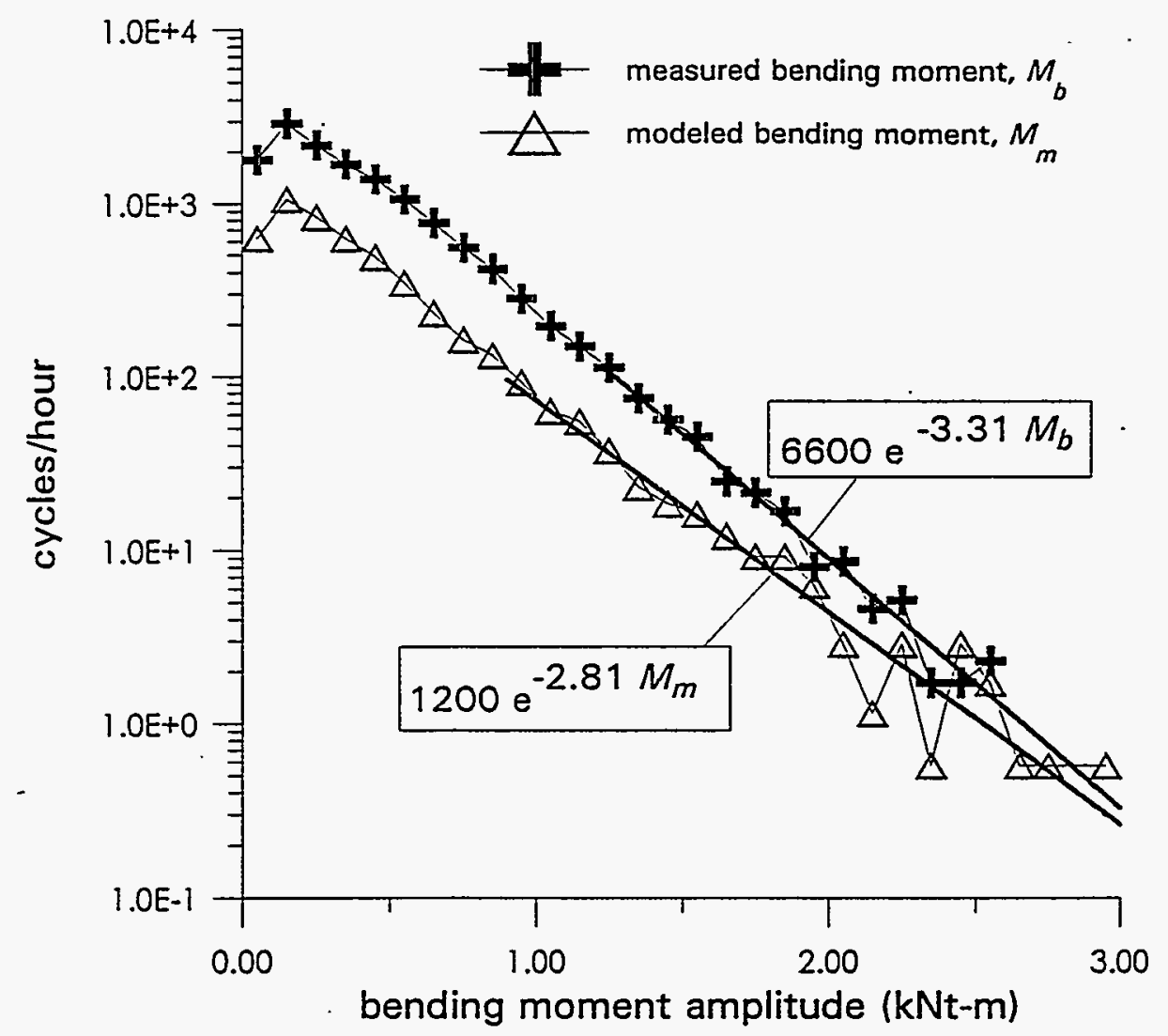

FIGURE 3.3. The Rainflow Count Distribution of the Measured Bending Moment, with an Exponential Fit to LCHA Region (cycles/hour $<100$ ).

Some differences between the two distributions are evident. For example, in the range of amplitudes from $0 \mathrm{kNt}-\mathrm{m}$ to about $2 \mathrm{kNt}-\mathrm{m}$, the model-derived curve is less than the curve obtained from the measured data. Apparently, this discrepancy is a consequence of leaving out the blade response, which would tend to boost the number of small amplitude cycles and thereby increase the cycle counts in this region. Furthermore, in the LCHA range, the tail of the distribution, the parameters of the exponential fit for one case are somewhat at variance with those from the other case. What effect might these differences have an overall damage rate calculation? If we assume that each distribution's tail can be extrapolated to infinity using the exponential fit, and that the exponential model is valid over the entire range of the bending moment amplitudes $(0$ to $\infty)$, then the relative damage is

$$
D=\int_{0}^{\infty} 10 \beta_{0} e^{-\beta_{1} M} M^{b} d M=10 \beta_{0} \beta_{1}^{-(b+1)} \Gamma(b+1)
$$


where $\Gamma$ is the gamma function. This is a particularly good approximation for large exponent materials. (The factor of 10 in Equation [13] accounts for the fact that the bending moment amplitude is binned in increments of $0.1 \mathrm{kNt}-\mathrm{m}$; i.e., $10 \beta_{0} \exp (-\beta, M)$ is a density such that $\int_{0}^{\infty} 10 \beta_{0} \exp (-\beta, M) d M$ is equal to the total number of cycle counts per hour.) Taking $b$ equal to 13.5 , the overall relative damage rates are $7.7 \times 10^{7}$ and $1.5 \times$ $10^{8}$ (with units of [relative damage]/hr) for the "measured" and modeled cases, respectively. The agreement is good to an order of magnitude, and considering that we are just seeking only an estimate, we conclude that our simple bending moment model works reasonably well. 



\subsection{Summary}

The goal of this paper is to provide a means of estimating turbine blade fatigue at potential wind turbine sites. This objective was achieved by making a connection between conventional wind measurements and the root flap bending moment though the use of a simple model. The model simulates the times series of the root flap bending moment from which fatigue estimates can be made. In this manner, the connection between the wind and turbine blade fatigue is established. The technique presented here is not intended to replace more sophisticated fatigue analyses, but rather to serve as a simple "rule of thumb" for convenient and inexpensive use by the wind energy community.

The technique was tested by comparing fatigue estimates derived from measured bending moment data with corresponding estimates obtained from the model. The agreement between the two estimates is very good, and the technique can readily distinguish between low- and high-fatigue cases. By contrast, the turbulence intensity fails miserably as a predictor of fatigue damage.

The required wind measurements necessary for input to the model can be obtained from three anemometers mounted on a single tower, sampled at a rate of about $5 \mathrm{~Hz}$. These measurements may be made as part of a routine resource assessment program. The low cost involved with these measurements and the simplicity of the bending moment model make the technique presented here a practical way of assessing the potential for blade fatigue damage at prospective wind turbine sites. 


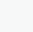

. 


\subsection{References}

Butterfield, C. P., W. P. Musial, and D. A. Simms. 1992. Combined Experiment Phase I Final Report. NREL/TP-257-4655, National Renewable Energy Laboratory, Golden, Colorado.

Connell, J. R., V. R. Morris, D. C. Powell, and G. L. Gower. 1988. The PNL Single-Tower Measurement Model of Rotationally Sampled Turbulent Wind, with User's Guide for STRS2PC. PNL-6580, Pacific Northwest Laboratory, Richland, Washington.

Downing, S. D., and D. F. Socie. 1982. "Simple Räinflow Counting Algorithms." Int. J. Fatigue 4(1):191-198.

George, R. L., and J. R. Connell. 1984. Rotationally Sampled Wind Characteristics and Correlations with MOD-OA Wind Turbine Response. PNL-5238, Pacific Northwest Laboratory, Richland, Washington.

Jackson, K. L. 1994. "Scaling Wind Turbine Fatigue Design Loads." In Thirteenth ASME Wind Energy Symposium, SED-Vol. 15, ed. W. D. Musial, American Society of Mechanical Engineers.

Kelley, N. D. 1994. "The Identification of Inflow Fluid Dynamics Parameters that Can be Used to Scale Fatigue Loading Spectra of Wind Turbine Structural Components." In Thirteenth ASME Wind Energy Symposium, SED-Vol. 15, ed. W. D. Musial, American Society of Mechanical Engineers.

Mandell, J. F. , R. M. Reed, D. D. Samborsky, and P. Qiong. 1993. "Fatigue Performance of Wind Turbine Blade Composite Materials." In Twelfth ASME Wind Energy Symposium, SED-Vol. 14, ed. S. Hock, American Society of Mechanical Engineers.

Smedman, A-S. 1992. "Calculations of Dynamic Wind Turbine Blade Loads from Simple Meteorological Data." Wind Engineering 16(4):195-212.

Sutherland, H. J., P. S. Veers, and T. D. Ashwill. 1995: "Fatigue Life Prediction for Wind Turbines: A Case Study on Loading Spectra and Parameter Sensitivity." In Case Studies for Fatique Education, ASTM STP 1250, ed. Ralph 1. Stephens, American Society for Testing and Materials, Philadelphia.

Wilson, R. E. 1994. "Aerodynamic Behavior of Wind Turbines." In Wind Turbine Technology, ed. D. A. Spera, AMSE Press, New York. 
Wendell, L. L., J. C. Barnard, and V. R. Morris. 1993. "New Parameters for Characterizing Turbulence at a Potential Wind Site." In Proceedings of the Windpower '93 Conference, American Wind Energy Association, San Francisco. 


\section{Distribution}

No. of

Copies

\section{OFFSITE}

12 DOE/Office of Scientific and Technical Information

D. F. Ancona

EE-121/FORS

U.S. Department of Energy 1000 Independence Ave., SW Washington, DC 20585

\section{J. B. Cadogan}

EE-121/FORS

U.S. Department of Energy 1000 Independence Ave., SW Washington, DC 20585

C. C. Castellano

EE-121/FORS

U.S. Department of Energy 1000 Independence Ave., SW Washington, DC 20585

B. H. Bailey, President AWS Scientific, Inc. 3 Washington Square Albany, NY 12205-5591

D. Bain

Oregon Department of Energy 6935 SW 45th Avenue Portland, OR 97219-1506

D. W. Bernadett AWS Scientific, Inc. 3 Washington Square Albany, NY 12205
No. of

Copies

D. Blittersdorf, President NRG Systems, Inc. 110 Commerce Street Hinesburg, VT 05461

C. P. Butterfield Senior Engineer

National Renewable Energy Laboratory 1617 Cole Boulevard Golden, CO 80401

K. Cohn Operations Manager Second Wind Inc.

7 Davis Square

Somerville, MA 02144

E. L. Davis Manager, Wind Power Integration Electric Power Research Institute 3412 Hillview Avenue P.O. Box 10412 Palo Alto, CA 94303

R. Doskeland Windland, Inc. 10448 Garverdale Court \#606 Boise, ID 83704-5474

D. M. Eggleston, Principal DME Engineering P.O. Box 5907 Midland, TX 79704-5907 
No. of

Copies

D. L. Elliott

Senior Scientist

National Renewable Energy

Laboratory

1617 Cole Boulevard

Golden, CO 80401

M. Gagner

FloWind Corporation

990 A Street, Suite 300

San Rafael, CA 94901

M. Haller

Enercon U.S. Division

P.O. Box 883

Hudson, WI 54016-883

C. Hansen

University of Utah

Dept. of Mechanical Engineering

Salt Lake City, UT 84112

P. Hughes

Atlantic Orient Corporation

41 Martha's Lane

South Harwich, MA 02661

S. M. Hock

Manager, Wind Energy Program

National Renewable Energy

Laboratory

1617 Cole Boulevard

Golden, CO 80401

Dr. W. E. Holley

Kenetech

6952 Preston Avenue

Livermore, CA 94550
No. of

Copies

\author{
N. D. Kelley \\ National Renewable Energy \\ Laboratory \\ 1617 Cole Boulevard \\ Golden, CO 80401-3393 \\ J. Kline \\ RAM Associates \\ P.O. Box 932 \\ Oakley, CA 94561 \\ E. McCarthy \\ Wind Economics \& Technology, Inc. \\ P.O. Box 1971 \\ Martinez, CA 94553 \\ M. McMullen \\ FloWind Corporation \\ 990 A Street, Suite 300 \\ San Rafael, CA 94901 \\ B. McNiff, Principal \\ McNiff Light Industry \\ 487 Bedford Road \\ Carlisle, MA 01741
}

A. Mikhail

Zond Systems, Inc.

P.O. Box 1910

Tehachapi, CA 93581

L. W. Miles

Wind Turbine Company

515116 th Avenue, Suite 263

Bellevue, WA 98004

E. Moroz

University of Texas at El Paso

Mechanical and Industrial

Engineering Department

El Paso, TX 79968

Distr. 2 
No. of

Copies

R. Nierenberg

Consulting Meteorologist

153 Sacramento Avenue

San Anselmo, CA 94960

G. A. Quandt

P.O. Box 4398

Pocatello, ID 83205

H. J. Sutherland

Technical Staff - Wind Energy Dept.

Sandia National Laboratories

P.O. Box 5800, MS 0708

Albuquerque, NM 87185-0708

A. Swift

Professor of Mechanical Engineering

University of Texas, El Paso

Dept. Mechanical and Industrial

Engineering

500 W. University Ave.

El Paso, TX 79968-0521

R. W. Thresher, Director

National Wind Technology Center

National Renewable Energy

Laboratory

1617 Cole Boulevard

Golden, CO 80401-3393
No. of

Copies

W. A. Vachon

W. A. Vachon \& Associates, Inc.

P.O. Box 149

Manchester, MA 01944

P. S. Veers

Senior Technical Staff

Sandia National Laboratories

Division 6214, MS 0708

Albuquerque, NM 87185

\section{ONSITE}

DOE Richland Operations Office

J. K. Schmitz

13 Pacific Northwest Laboratory

J. C. Barnard (5)

V. R. Morris

L. L. Wendell

Publishing Coordination

Technical Report Files (5) 